\title{
Midwife-led obstetric units working 'CLEVER': Improving perinatal outcome indicators in a South African health district
}

\author{
S J Oosthuizen, ${ }^{1} \mathrm{MB}$ ChB, MMed (Fam Med); A-M Bergh, ${ }^{2} \mathrm{PhD}$; J Grimbeek, ${ }^{2} \mathrm{MSc}$; \\ R C Pattinson, ${ }^{2,3}$ BSc, MB BCh, MMed (O\&G), FCOG (SA), MD, FRCOG \\ ${ }^{1}$ Tshwane District Health and Department of Family Medicine, School of Medicine, Faculty of Health Sciences, University of Pretoria, South Africa \\ ${ }^{2}$ South African Medical Research Council Maternal and Infant Health Care Strategies Unit, Faculty of Health Sciences, University of Pretoria, \\ South Africa \\ ${ }^{3}$ Department of Obstetrics and Gynaecology, School of Medicine, Faculty of Health Sciences, University of Pretoria, South Africa
}

Corresponding author: S J Oosthuizen (sarie.silberbauer@gmail.com)

\begin{abstract}
Background. South Africa did not meet its Millennium Development Goals with regard to the reduction in maternal and under-5 mortality. Furthermore, many birthing women do not receive intrapartum care with empathy and endure disrespectful and abusive care.

Objectives. To implement a multicomponent, context-specific intervention package to change the complex interplay between preventable maternal and perinatal mortality and morbidity and poor clinical governance and supervision in midwife-led labour units.

Methods. A mixed-methods intervention study was conducted in Tshwane District, South Africa, in 10 midwife-led obstetric units (MOUs), from which a purposive sample consisting of five units was selected for the intervention. The intervention took place in three phases: (i) baseline measurement; (ii) implementation of the so-called 'CLEVER' intervention package in the five intervention units, based on the results of the first phase; and (iii) a review of health systems improvements and perinatal outcomes. The intervention had three pillars: $(i)$ feedback of the baseline measurement to the intervention units to raise awareness and solicit participation; (ii) health systems strengthening; and (iii) intensive weekly engagement for 3 months, with further monthly support afterwards. Observation of barriers during baseline activities contributed to the health systems strengthening and improvement strategies during implementation.

Results. Perinatal outcome indicators for the year before the intervention were compared with data for the year in which the intervention took place and the year after the intervention. Significant declines were observed in in-facility fresh stillbirths, meconium aspiration and birth asphyxia in the intervention MOUs from 2015 to 2017. The control group showed some decline during the period owing to support from district clinical specialist team members.

Conclusions. CLEVER as a context-specific, multicomponent, clinically focused intervention package may have contributed to improved perinatal morbidity and mortality rates in MOUs.
\end{abstract}

S Afr Med J 2019;109(2):95-101. DOI:10.7196/SAMJ.2019.v109i2.13429

Essential maternal and newborn care and the effective management of complications contribute to the survival and improved wellbeing of the mother-infant pair and are linked to improved individual and facilitylevel outcomes. ${ }^{[1]}$ Although more deliveries are now performed by skilled birth attendants, healthcare during childbirth is not always safe, timely, equitable or person centred. ${ }^{[2]}$ Previously, these individuals' skills or attitudes were blamed for poor-quality care that led to mortality. ${ }^{[3]}$ The focus has now shifted to health systems strengthening ${ }^{[4]}$ to provide a safe environment for quality obstetric care. In addition, the emphasis is on taking the needs and perceptions of the community into account and giving appropriate feedback to the community. ${ }^{[5,6]}$

In many low- and middle-income countries (LMICs), suboptimal intrapartum care and an added burden of poorly functioning health systems contribute to the slow reduction in maternal and neonatal mortality and morbidity. ${ }^{[7]}$ South Africa (SA), a middle-income country, did not reach its Millennium Development Goals 4 and 5 targets. Multicomponent interventions targeting local health system barriers $^{[8,9]}$ and using the World Health Organization (WHO) Quality of Care framework ${ }^{[10]}$ have demonstrated the possibility of reducing preventable mortality and morbidity during childbirth. ${ }^{[1,11,12]}$ 'CLEVER' is a multicomponent, context-specific intervention package designed to address these symptoms according to the latest evidence on implementation ${ }^{[13,14]}$ and behaviour change. ${ }^{[15-17]}$ The package was developed to involve the micro-, meso- and macro- levels of the district health system in a subdistrict of SA to promote sustainability of improved obstetric care practices and respectful, competent midwife-led quality care during labour and delivery in midwife-led obstetric units (MOUs).

CLEVER is the acronym for Clinical care, Labour ward management, Eliminate barriers, Verify care, Emergency obstetric simulation training, and Respectful care. Planning for implementation was done with a stages-of-change framework that has been used in SA in the field of obstetric and neonatal care. ${ }^{[13,14]}$ The implementation uses a three-pillar strategy: (i) baseline assessment with feedback to raise awareness and solicit participation; (ii) health systems strengthening; and (iii) an intensive 3-month engagement period, with further follow-up support. Pillars one and two run concurrently.

\section{Objectives}

To report on the implementation of the CLEVER package and the evaluation of its impact. The objectives of the evaluation were to measure the change over time with regard to three key perinatal outcomes, namely fresh stillbirths, meconium aspiration and intrapartum-related respiratory depression.

\section{Methods}

A three-phase, mixed-methods intervention study was conducted in Tshwane District, SA, in 2016 (Fig. 1). The development and 


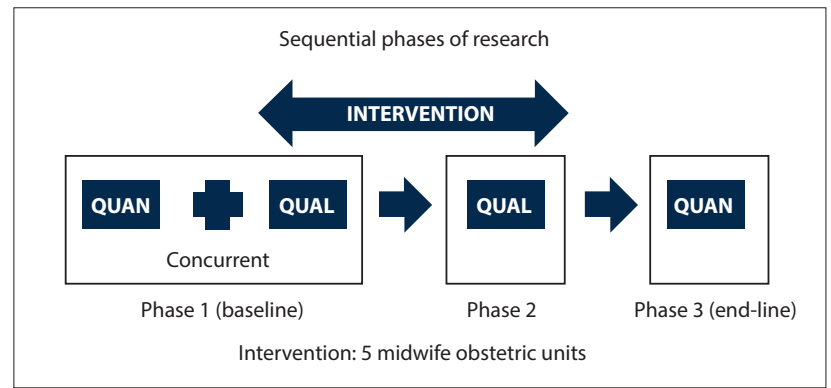

Control: 5 midwife obstetric units

Fig. 1. The mixed-methods research design. (QUAN = quantitative; $Q U A L=$ qualitative.)

implementation of the CLEVER package formed the backbone of the intervention phase.

The study was approved by the Research Ethics Committee of the Faculty of Health Sciences, University of Pretoria (ref. no. 541/2015) and the Tshwane District Research Committee (ref. no. 62/2015). The facility managers and midwives of all the MOUs provided written permission for participation, and clients participated voluntarily and anonymously.

\section{Research setting}

Tshwane District has 10 MOUs rendering basic obstetric care for lowrisk deliveries and referring women in need of higher levels of care to district hospitals. All units were included in the baseline and end-line assessment activities.

In 2015, the 10 MOUs managed a total of 8645 deliveries. All shifts in the five bigger MOUs consisted of three midwives, including an advanced midwife, while the smaller units had two to three midwives per shift, including an advanced midwife. The smaller units did not have midwives dedicated exclusively to deliveries, and they also had to assist with primary healthcare clients during night shifts.

Five MOUs located in one subdistrict and under the same management supervision were purposively selected for the implementation of the intervention. These units were the more disadvantaged health facilities in the district. The other five units in the remaining subdistricts were included as control units. A randomised controlled trial was not feasible because of the high probability of contamination. The context of all the units is described in more detail in online supplementary file 1 (http:// samj.org.za/public/sup/Supplementary\%20table\%201\%20MOU\%20 background\%20information\%20(1).pdf).

\section{Data collection and analysis at baseline and end-line}

Different data collection strategies were followed during the three phases of the study. Some of the main methods are discussed below.

Phase 1. Preimplementation observations of the functioning of intervention and control units and the quality of care and teamwork were recorded as field notes, using a structured observation sheet. A baseline survey of women's experiences of childbirth was conducted in all 10 MOUs. ${ }^{[18]}$ In the five intervention units, additional qualitative data were collected by means of five group discussions with 31 pregnant women awaiting antenatal care, five focus groups with 20 midwives, and individual interviews with the five facility managers and the five nominated midwife team leaders.

Phase 2. Minutes of all meetings held with the midwife team leaders were collated as data sources. The last meeting with midwife team leaders describing changes in MOUs during and after implementation was audio-recorded and transcribed. The data were analysed qualitatively in order to understand the change processes.

Phases 1 and 3. Perinatal indicator statistics for the baseline and end-line assessments were derived from the District Health Information System and on-site birth registers for all 10 MOUs. The interpretation of the definitions of these conditions did not change during the period of data collection. Intrapartum fresh stillbirths were counted for fetuses with a mass $>1000 \mathrm{~g}$ alive on admission to the MOU, but stillborn at delivery. ${ }^{[19]}$ Morbidity was limited to term neonates with Apgar scores $<7-8$ after 5 minutes, with difficulty in respiration, and who had been transferred to hospital-level care. Midwives' recordings of the clinical diagnosis in the birth register as 'meconium aspiration' or 'birth asphyxia' were counted.

\section{Data analysis of perinatal statistics}

SAS 9.4 (SAS Institute, USA) was used for statistical analysis. ${ }^{[20]}$ Statistical significance was judged to be at the $2 \%$ level. Owing to the variation in data, the LOESS smoothing technique ${ }^{[21]}$ was applied to the raw monthly values of the rates for fresh stillbirth, birth asphyxia and meconium aspiration, with linear regression lines fitted to the smoothed data points, for the control and intervention groups, respectively. The period considered was January 2015 - December 2017. The objective of this approach was not to fit a curve but to describe the overall trend over the 3-year period. The three annual data points were insufficient to justify the fit of a straight line. The total data set can be found in online supplementary file 2 (http:// samj.org.za/public/sup/Supplementary\%20table\%202\%20Data\%20 key\%20indicators\%202015-2017\%20(1).pdf).

\section{Implementation of the CLEVER package}

The CLEVER package was implemented under mandate of the district clinical specialist team (DCST) of Tshwane District. A DCST is a multiprofessional cluster of healthcare workers created in each district in SA in 2012 to embark on quality improvement projects in maternal, newborn and child health. ${ }^{[22]}$ Members of a DCST can move between the levels of care in a district to collaborate with multidisciplinary members of healthcare teams in order to effect change as role models or as implementation facilitators. The first author was the DCST member who acted as internal facilitator of the intervention. She did not visit the control units during the active intervention period, but the other members of the DCST continued with the standard treatment for MOUs, which included monthly visits and emergency drills. The implementation schedule and methods are shown in Table 1.

The intensive 3-month engagement period for the implementation of the CLEVER package extended from May to July 2016. Supervisory and cognitive behaviour change activities targeted the following high-priority areas: essential childbirth and newborn care including labour monitoring; management of pre-eclampsia, eclampsia and complications; postpartum haemorrhage; correct management of difficult labour during breech and shoulder dystocia; newborn resuscitation; management of preterm labour, birth, and preterm and small babies; and management of maternal and newborn infections. ${ }^{[1]}$ Ongoing support of team leaders continued until the end of 2016 to strengthen the changes and support the sustainability of improvements. DCST members continued their monthly visits to all MOUs.

\section{Results}

Individualised health systems strengthening took place in the first phase of the study, before the implementation of the CLEVER package in the second phase. In the third phase, a comparison 


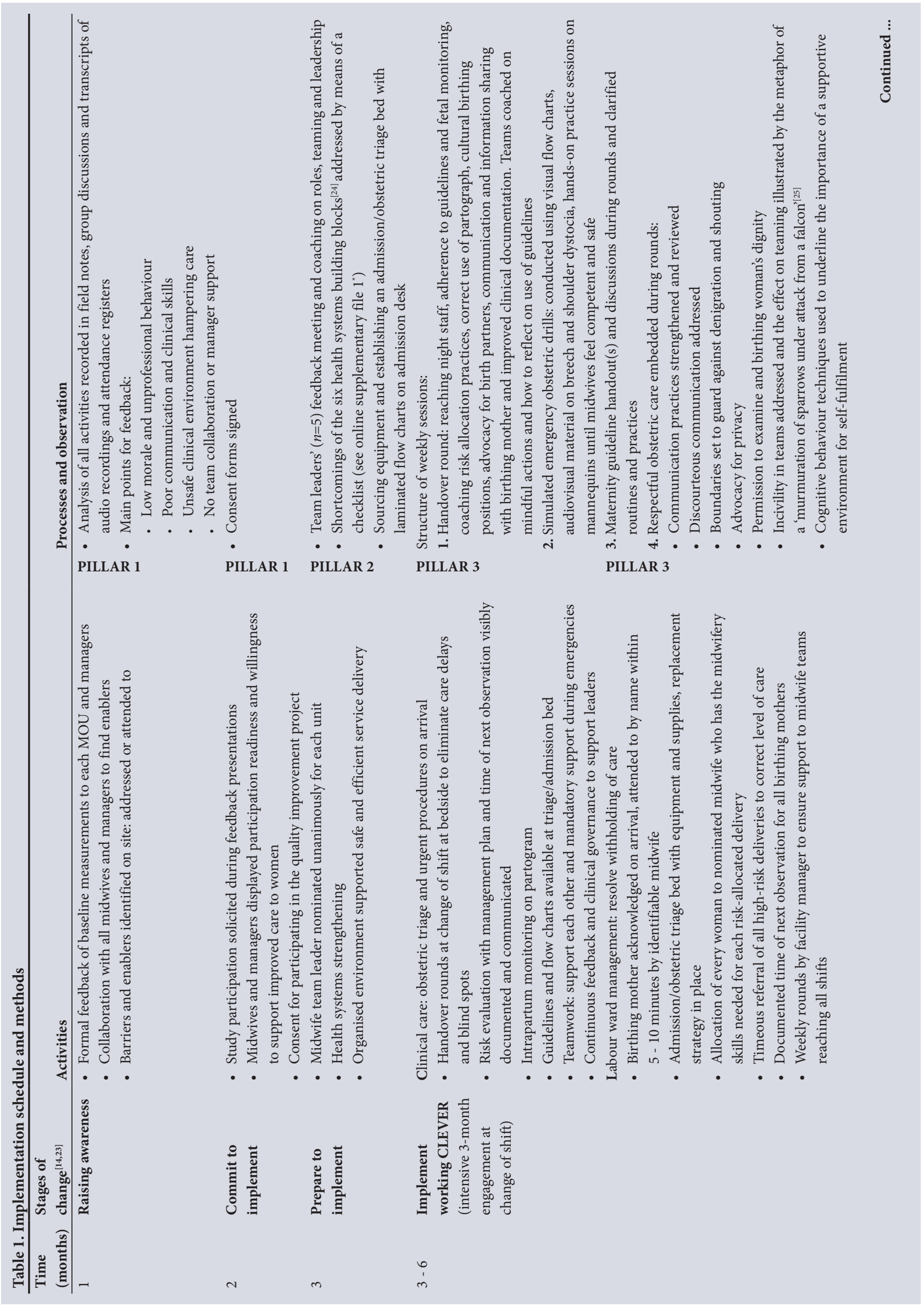




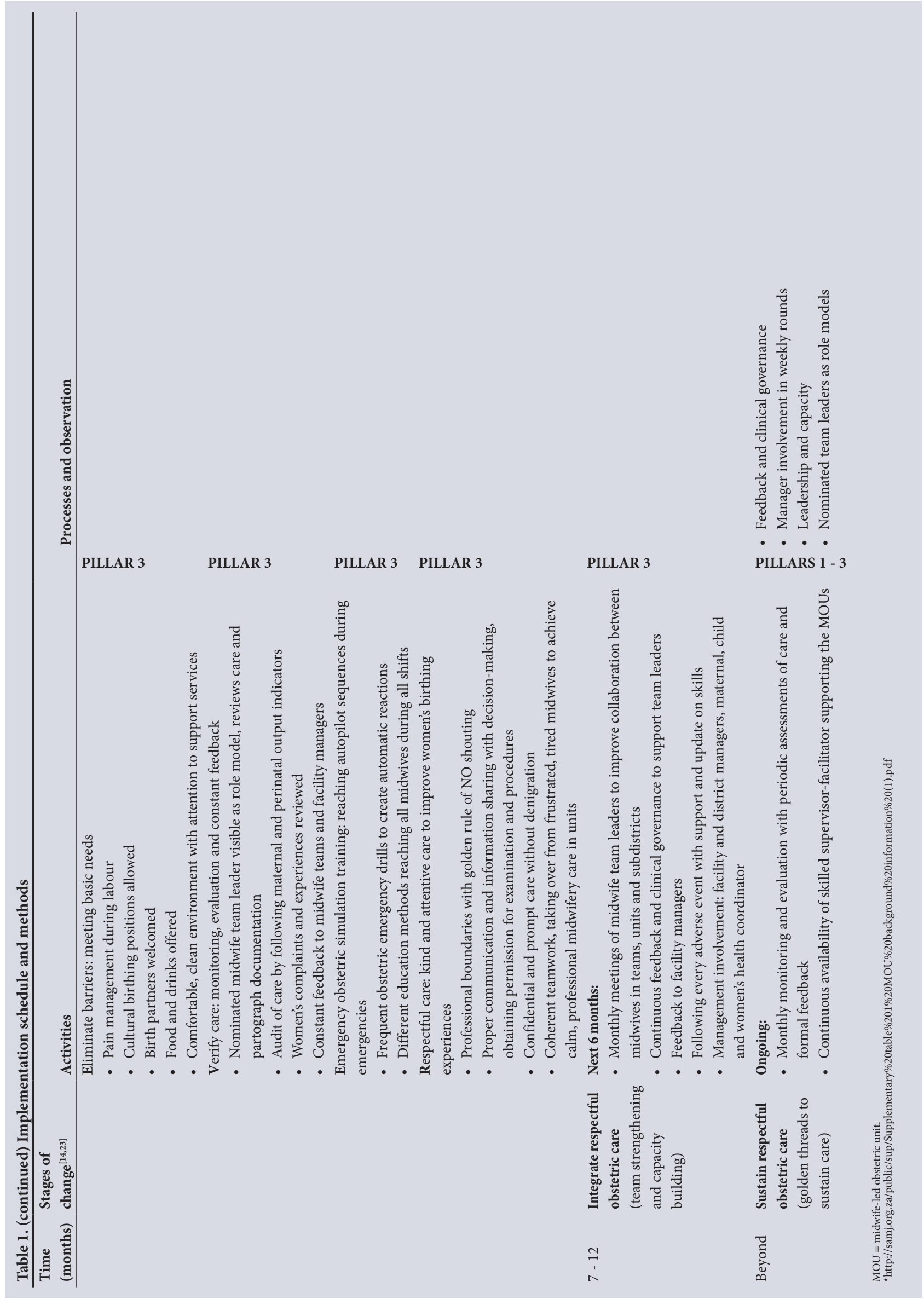


was made between the baseline and end-line results with regard to changes in perinatal outcomes.

\section{Phase 1: Health systems strengthening}

Changes in the health system were recorded according to the six WHO health systems building blocks. ${ }^{[2]}$ These changes were contextualised for each intervention MOU and are described in detail in online supplementary file 3 (http://samj.org.za/public/ sup/Supplementary\%20table $\% 203 \% 20$ Health $\% 20$ systems $\% 20$ strengthening\%20(1).pdf). A few examples of major changes are the set-up of emergency care areas to function as obstetric triage and admission, the restoration of the functionality of referral routes, and supplementation of medical products and supplies.

\section{Phase 2: Implementation of the CLEVER package}

Working 'CLEVER' was rolled out during the early-morning changeof-shift rounds following the activities described in Table 1, namely handover rounds, simulated emergency obstetric drills, maternity guideline handout(s) and discussions. Respectful obstetric care was embedded in all actions.

One unit experienced interruptions to the schedule owing to community unrest and a public holiday, delaying the process by 2 weeks. The same unit's team leader was taken ill, and another lead midwife had to be nominated after 4 weeks. A second unit was temporarily closed for refurbishment after the intensive 3-month engagement. All midwives and birthing women were transferred to one of the other intervention units.

Sixty simulated emergency obstetric drills were conducted during the intensive engagement period, reaching midwives in all shifts in the five intervention units and accounting for 362 individual exposures for these midwives. Midwives who had missed some of the sessions were given the opportunity to catch up after the early morning rounds until they were able to demonstrate proficiency in skills. In the control MOUs, other DCST members conducted 17 drills, comprising 46 individual exposures. Maternity guideline handouts and clinical discussions only took place in the intervention units and provided an educational opportunity for some of the midwives who had not been able to go for updates or further training.

\section{Phase 3: Comparison of baseline and end-line results}

Significant declines were observed in the number of in-facility fresh stillbirths and cases of meconium aspiration and birth asphyxia in the intervention MOUs from 2015 to 2017. The results for the fitted regression lines are summarised in Table 2, and Figs 2 - 4 depict the change trends in perinatal outcomes over the same period.

Results based on LOESS smoothing indicate that the rate of fresh stillbirths per 1000 births decreased at a higher rate for the intervention group than the control group during the period under consideration. The smoothed graphs in Fig. 2 show an increase for the intervention group from January 2015 to about August 2015, followed by a rapid decrease to July 2016 and a more gradual decrease to December 2017. The decrease in fresh stillbirths in the control group followed a more constant pattern over the period January 2015 - December 2017.

With regard to birth asphyxia, the starting level was at a rate of 5.092 per 1000 live births for the control group and 14.132 for

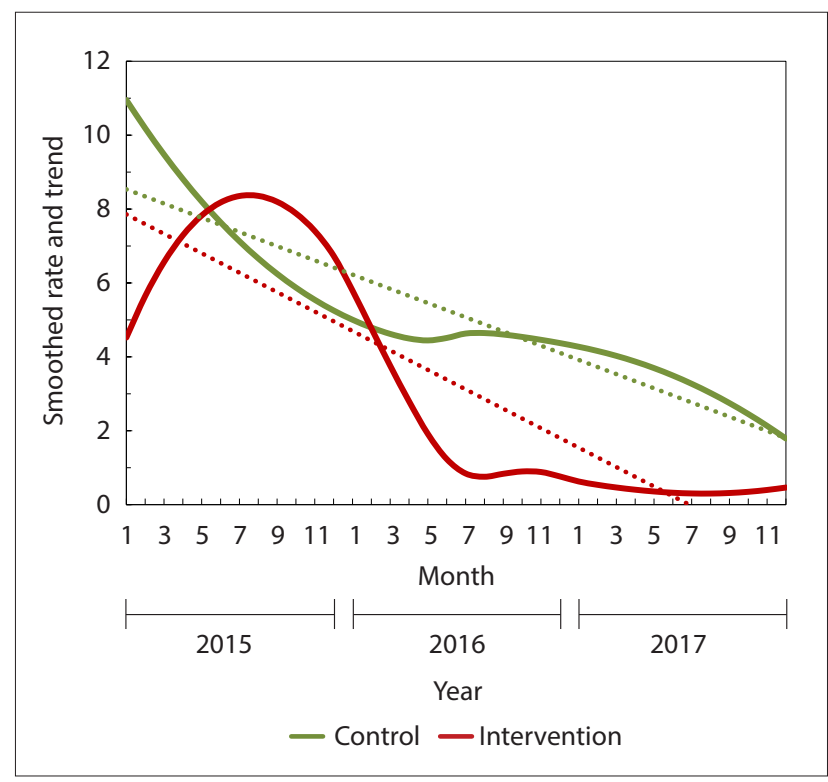

Fig. 2. Fresh stillbirth rate per 1000 births over a 3-year period.

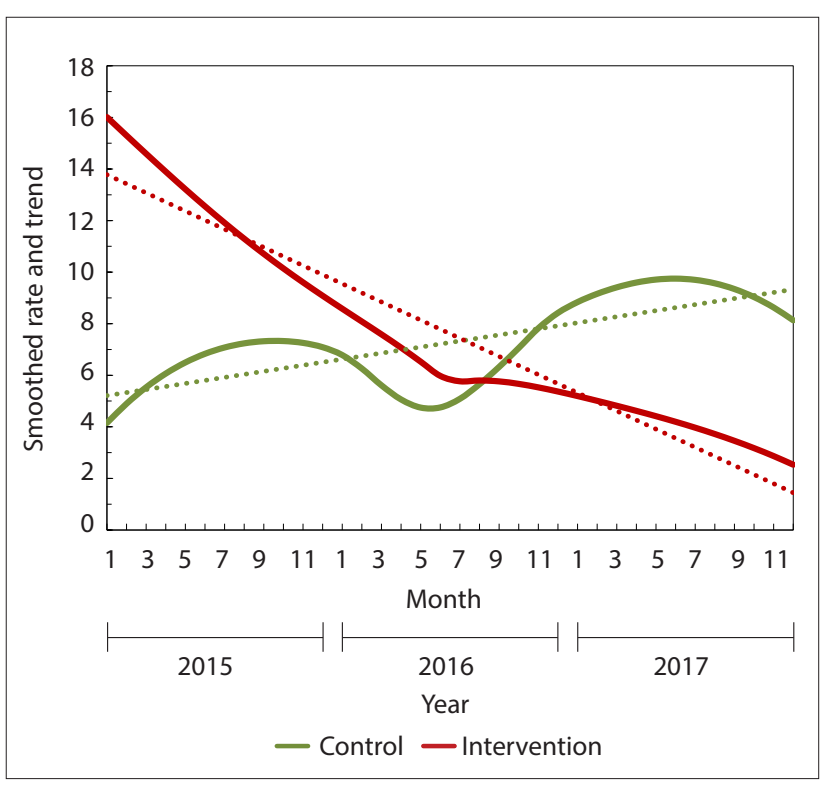

Fig. 3. Birth asphyxia rate per 1000 live births over a 3-year period.

Table 2. Fitted linear regression lines for the three main indicators

\begin{tabular}{|c|c|c|}
\hline Fresh stillbirth rate $(s)$ & Birth asphyxia rate $(b)$ & Meconium aspiration rate $(m)$ \\
\hline$\hat{\boldsymbol{s}}_{\text {Control }}=8.726-0.192 \times$ Month & $\hat{\boldsymbol{b}}_{\text {Control }}=5.092+0.117 \times$ Month & $\hat{m}_{\text {Control }}=3.951-0.028 \times$ Month \\
\hline$\hat{\boldsymbol{S}}_{\text {Intervention }}=8.119-0.263 \times$ Month & $\hat{b}_{\text {Ittervention }}=14.132-0.353 \times$ Month & $\hat{m}_{\text {Intervention }}=12.198-0.322 \times$ Month \\
\hline Intercepts (8.726 v. 8.119) not significantly & Intercepts (5.092 v. 14.132) and slopes (0.117 & Intercepts (3.951 v. 12.198) and slopes \\
\hline different $(p=0.3304)$ & v. -0.353 ) both significantly different, each at & $(-0.028$ v. -0.322$)$ both significantly \\
\hline Slope of Intervention $(-0.263)$ significantly more & $p<0.0001$ & different, each at $p<0.0001$ \\
\hline \multicolumn{3}{|l|}{ negative than that of Control $(-0.192)(p=0.0180)$} \\
\hline $2015($ Month $=1), \ldots$, December $2017(M$ & th $=$ & \\
\hline
\end{tabular}




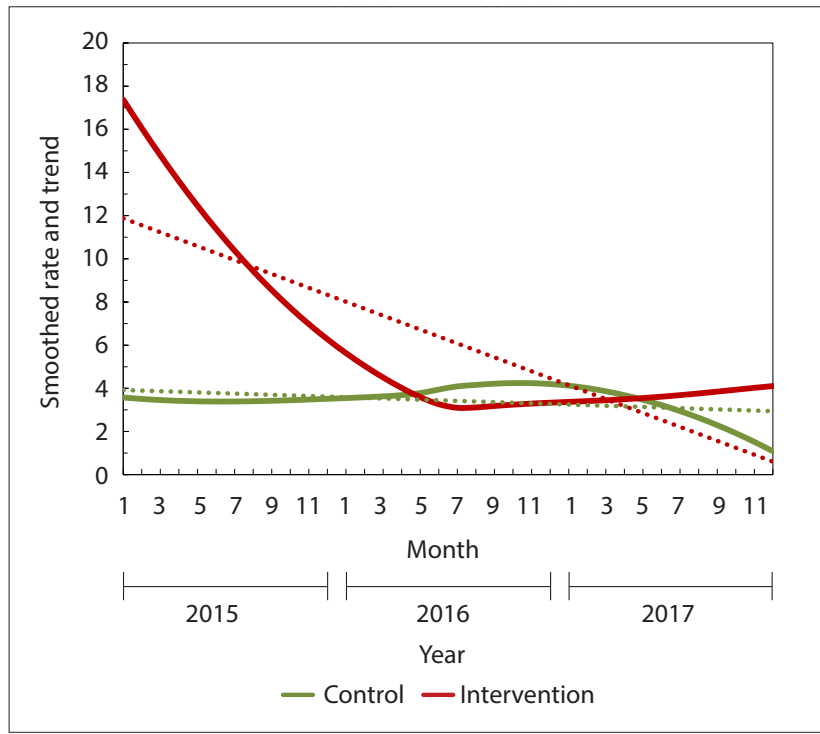

Fig. 4. Meconium aspiration rate per 1000 live births over a 3-year period.

the intervention group. In the control group, the birth asphyxia rate dropped initially and then increased again. The smoothed graphs in Fig. 3 show a varying increase for the control group and a steady decrease for the intervention group over the period January 2015 - December 2017. On average, the rate increased at 0.177 per month for the control group and decreased at a rate of 0.353 for the intervention group.

With regard to meconium aspiration, the starting level was a rate of 3.951 per 1000 live births for the control group and 12.198 per 1000 live births for the intervention group. On average, the rate decreased by 0.028 per month for the control group and 0.322 for the intervention group. The smoothed graphs in Fig. 4 show a relatively fast decrease in the meconium aspiration rate from January 2015 to July 2016 for the intervention group and a slow increase thereafter. The rate for the control group stayed at around the same level up to December 2016, followed by a more rapid decline. Generally speaking, the rate declined more per month for the intervention group.

\section{Discussion}

This study examined the outcomes of working CLEVER with regard to perinatal indicators associated with quality obstetric care in midwife obstetric units. Interventions in quality of care ${ }^{[27]}$ and health systems strengthening are regarded as the main foundations for improving health systems outputs. ${ }^{[24]}$ In our study, health systems strengthening was tailored to the needs of each intervention unit. Combinations of safe healthcare environments with adequate supportive equipment, drugs and supplies, in conjunction with clinical governance and accountability, are regarded as strong motivators for better midwifery care. $^{[28]}$

Many studies have called for more action on substandard obstetric care, while also addressing principles of respectful care and cultural sensitivity. ${ }^{[26,29-32]}$ The WHO Safe Childbirth Checklist programme in India was implemented with peer coaching. Birth attendants were coached to use the checklist, identify gaps in care and activate resources through the healthcare system. Although the utilisation of the checklist remained significantly higher in the intervention facilities throughout the trial, adherence was not sustained and decreased after coaching was concluded. There was no significant effect on maternal and perinatal health outcomes. ${ }^{[33]}$ In our study, supportive supervision and coaching during handover rounds at change of shift, with further capacity building, were embedded in the CLEVER package to ensure improved clinical performance and reduced risk in the labour ward. Effective risk management was based on the high-priority areas identified in the literature. ${ }^{[1]}$ Local barriers that may impact on motivation to adhere to guidelines and best practices were addressed by improved collaboration between managers. ${ }^{[3,24,34]}$ Midwife leaders working with their teams ${ }^{[35]}$ enhanced supportive teamwork and shared-decision communication practices between managers, midwives and birthing women.

The combination of a number of known elements of highquality obstetric care embedded in the CLEVER package may have contributed to the significant reduction in avoidable fresh stillbirths, meconium aspiration and birth asphyxia in the intervention units. These include the following: improvements in the safety of the labour environment; handover at change of shift, ${ }^{[36-38]}$ extending to the night staff; ${ }^{[8]}$ obstetric triage, ${ }^{[39]}$ with early identification of risk and timely transfer out; addressing of barriers: $;^{[9,10,24]}$ and audits and feedback. ${ }^{[35,40,41]}$ Quality care was further reinforced by respectful communication, appropriate risk management and improved teamwork, ${ }^{[42]}$ resulting in the identification of blind spots with regard to complications and earlier referral. The increased number of simulation training events in the intervention units could possibly explain the consistent decrease in birth asphyxia in the intervention units, compared with an increase in the control units in 2017. Studies on Helping Babies Breathe and simulation training reported a similar decrease in mortality, and an increase in birth asphyxia identification and treatment. ${ }^{[43]}$

\section{Study limitations}

The study had several limitations. Logistical constraints related to protest action and a public holiday have already been mentioned. The intervention facilities are situated in the northern part of the district where long distances hindered previous support and outreach programmes, leaving these units as poorer performers in the district. It is also acknowledged that facilitator bias could play an important role during implementation and outcome measurement. In order to prevent observer bias, key perinatal indicators were selected for formal measurement at the beginning (2015) and end (2016) of the study, as well as 1 year after the intervention (2017), to be able to report on outcomes and sustainability. The objective of this study was to determine the effect of a complex, multicomponent intervention, and it is impossible to determine the exact effect of individual components.

We acknowledge the statistical limitations of the data analysis approach that was followed. Owing to the short time period of this study and the variation in the calculated mortality and morbidity rates, it was not possible to follow a time series approach, which would have been preferable. A third-degree polynomial fit could describe the curves more accurately, but this would not have demonstrated the general trend in improvement in the intervention MOUs.

While the study was limited to one district, the intervention makes provision for the context of an obstetric unit. The golden threads of continuous feedback, the linking of managers at the different levels of the district health system, capacity building of midwives with nominated champions and ongoing clinical governance are transferable to other obstetric units. The sustained care in obstetric practice may be ascribed to the linking of quality midwifeled obstetric care teamwork ${ }^{[35]}$ with continuous health systems strengthening ${ }^{[24]}$ built into the intervention, through the essential 
support of the DCST. ${ }^{[22]}$ Further research is needed to determine remaining knowledge gaps and the feasibility of implementing the CLEVER package at district hospitals.

\section{Conclusions}

The implementation of the principles of the CLEVER package may be transferable to other midwife-led units in LMICs to assist in the improvement of maternal and perinatal morbidity and mortality. The important perinatal indicators as a proxy of quality during 'working CLEVER' could potentially quantify the gap between the required care and reality, as many LMICs do not have a defined quality obstetric baseline to reach their sustainable development goals (SDGs). ${ }^{[14]}$ Health systems strengthening linked to quality obstetric care holds the key to progress towards the 2030 targets of the SDGs. Efficient teamwork, leadership and team simulation training are regarded as essential interventions to improve perinatal mortality, ${ }^{[35]}$ and clinical governance with formal feedback could result in adherence to highquality obstetric care practices. Implementing the CLEVER package also prepared the ground for future roll-out of obstetric quality improvement initiatives as, for example, described in the WHO Better Outcomes in Labour Difficulty (BOLD) project. ${ }^{[12,44]}$

Declaration. This publication is part of the $\mathrm{PhD}$ studies of the first author (SJO). Acknowledgements. The authors thank the healthcare professionals and clients who participated in the intervention. The following colleagues provided input and support: Peter Macdonald, Ute Feucht, Mothomone Pitsi, Lekwetji Komane, Lizzy Sithole, Rinah Skhosana, Mphai Tshukudu, Vivian Mfolo, Michelle Schele, Jenny Makin and Jannie Hugo.

Author contributions. All authors were involved in the design of the study. SJO performed the literature review and supervised the data collection. JG was responsible for the statistical analysis. SJO drafted the manuscript, which was reviewed and revised by A-MB, RCP and JG. All authors read and approved the final manuscript.

Funding. The South African National Department of Health and the South African Medical Research Council Unit for Maternal and Infant Health Care Strategies, University of Pretoria, provided financial support for the development and testing of the CLEVER package. The Department of Family Medicine, University of Pretoria, provided a research assistant. The funders played no further role in any part of the research.

Conflicts of interest. None.

1. Tunçalp Ö, Were WM, MacLennan C, Oladapo OT, Gulmezoglu AM, Bahl R. Quality of care for pregnant women and newborns - the WHO vision. BJOG 2015;122(8):1045-1049. https://doi.org/10.1111/14710528.13451

2. Bohren MA, Hunter EC, Munthe-Kaas HM, Souza JP, Vogel JP, Gülmezoglu AM. Facilitators and barriers to facility based delivery in low- and middle-income countries: A qualitative evidence synthesis. Reprod Health 2014;11:71. https://doi.org/10.1186/1742-4755-11-71

3. Berwick DM. Improvement, trust and the healthcare workforce. Qual Safety Health Care 2003;12(Suppl i):i2-i6. https://doi.org/10.1136/qhc.12.suppl_1.i2

4. Sharma G, Mathai M, Dickson KE, et al. Quality care during labour and birth: A multi-country analysis of health system bottlenecks and potential solutions. BMC Pregnancy Childbirth 2015;15(Suppl 2):S2. https://doi.org/10.1186/1471-2393-15-S2-S2

5. Srivastava A, Avan BI, Rajbangshi P, Bhattacharyya S. Determinants of women's satisfaction with maternal health care: A review of literature from developing countries. BMC Pregnancy Childbirth 2015:15:97. https://doi.org/10.1186/s12884-015-0525-0 6. Clark K, Beatty S, Reibel T. 'What women want': Using image theory to develop expectations of maternity
care framework. Midwifery 2015;31(5):505-511. https://doi.org/10.1016/j.midw.2014.12.011

care framework. Midwifery $2015 ; 31(5): 505-511$. https://doi.org/10.1016/j.midw.2014.12.011
7. Obara H, Sobel H. Quality maternal and newborn care to ensure a healthy start for every newborn in Obara H, Sobel H. Quality maternal and newborn care to ensure a healthy start for every newborn in
the World Health Organization Western Pacific Region. BJOG 2014;121(Suppl 4):154-159. https://doi. org/10.1111/1471-0528.12943

8. Abuya T, Ndwiga C, Ritter J, et al. The effect of a multi-component intervention on disrespect and abuse during childbirth in Kenya. BMC Pregnancy Childbirth 2015;15:224. https://doi.org/10.1186/s12884015-0645-6

9. Stokes T, Shaw EJ, Camosso-Stefinovic J, Imamura M, Kanguru L, Hussein J. Barriers and enablers to guideline implementation strategies to improve obstetric care practice in low- and middle-income countries: A systematic review of qualitative evidence. Implement Sci 2016;11:144. https://doi. org/10.1186/s13012-016-0508-1
10. World Health Organization. Standards for Improving Quality of Maternal and Newborn Care in Health Facilities. Geneva: World Health Organization, 2016. http://apps.who.int/iris/bitstre in Health Facilities. Geneva: World Health Organization, 2016. http:
am/10665/249155/1/9789241511216-eng.pdf?ua $=1$ (accessed 23 March 2018).

11. Lavender T. Improving quality of care during labour and childbirth and the immediate postnatal period. Lavender T. Improving quality of care during labour and childbirth and the immediate postnatal pe
Best Pract Res Clin Obstet Gynaecol 2016;36:57-67. https://doi.org/10.1016/.bpobgyn.2016.05.011

12. Bohren MA, Oladapo OT, Tunçalp Ö, et al. Formative research and development of innovative tools for

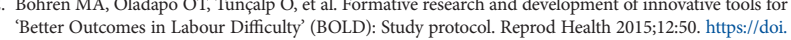
'Better Outcomes in Labour Diffiction

13. Bergh A-M, Allanson E, Pattinson R. What is needed for taking emergency obstetric and neonatal programmes to scale? Best Pract Res Clin Obstet Gynaecol 2015;29(8):1017-27. https://doi.org/10.1016/j. bpobgyn.2015.03.015

14. Belizán JM, Bergh A-M, Cilliers C, Pattinson RC, Voce A; Synergy Group. Stages of change: A qualitative study on the implementation of a perinatal audit programme in South Africa. BMC Health Serv Res 2011;11:243. https://doi.org/10.1186/1472-6963-11-243

15. Michie S, van Stralen M, West R. The behaviour change wheel: A new method for characterising and designing behaviour change interventions. Implement Sci 2011;6:42. https://doi.org/10.1186/1748-59086-42

6. Eccles MP, Grimshaw J, Walker A, Johnston M, Pitts N. Changing the behaviour of health care professionals: The use of theory in promoting the uptake of research findings. J Clin Epidemio 2005;58(2):107-112. https://doi.org/10.1016/j.jclinepi.2004.09.002

17. Godin G, Bélanger-Gravel A, Eccles MP, Grimshaw J. Healthcare professionals' intentions and behaviours: A systematic review of studies based on social cognitive theories. Implement Sci 2008;3:36. https://doi.org/10.1186/1748-5908-3-36

18. Oosthuizen SJ, Bergh AM, Pattinson R, Grimbeek J. It does matter where you come from: Mothers experiences of childbirth in midwife obstetric units, Tshwane, South Africa. Reprod Health 2017;14:151. https://doi.org/10.1186/s12978-017-0411-5

19. Lawn JE, Gravett MG, Nunes TM, Rubens CE, Stanton C, GAPPS Review Group. Global report on preterm birth and stillbirth (1 of 7): Definitions, description of the burden and opportunities to improve data. BMC Pregnancy Childbirth 2010;10(Suppl):S1. https://doi.org/10.1186/1471-2393-10-S1-S1

20. SAS/STAT 9.4 User's Guide. Cary, NC: SAS Institute, Inc., 2013.

20. SAS/STAT 9.4 User's Guide. Cary, NC: SAS Institute, Inc., 2013.
21. Cleveland W, Grosse E. Computable methods for local regression. Stat Comput 1991;1(1):47-62.

21. Cleveland W, Grosse E. Computable methods for local regression. Stat Comput 1991;1(1):47-62.
22. Ministerial Task Team. District Clinical Specialist Teams in South Africa: Ministerial Task Team Report Ministerial Task Team. District Clinical Specialist Teams in South Africa: Ministerial Task Team Repor
to the Honourable Minister of Health, Dr Aaron Motsoaledi. 2012. http://www.google.co.za/url?sa=t\&r to the Honourable Minister of Health, Dr Aaron Motsoaledi. 2012. http://www.google.co.za/url?sa=t\&
$\mathrm{ct}=j \& \mathrm{q}=\&$ esrc=s\&source=web\&cd=\&ved=0ahUKEwiY64fapN3RAhVLKMAKHYrUDxgQFgjMAE\&

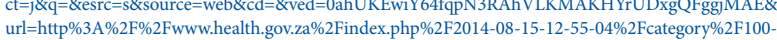
url=http\%3A\%2F\%2Fwww.health.gov.za\%2Findex.php\%2F2014-08-15-12-55-04\%2Fcategory\%2F100-
2012rp\%3Fdownload\%3D 186\%3Adistrict-clinical-specialist-teams-in-south-africa-ministerial-task2012rp\%3Fdownload\%3D 186\%3Adistrict-clinical-specialist-teams-in-south-africa-minister
team-report\&usg=AFQjCNFf4InCkNYzBB5uyOAFB1 wdR3A0fw (accessed 30 January 2018).

team-report\&usg=AFQjCNFf4InCKNYzBB5 4 uyOAFB1wdR3AOfw (accessed 30 January 2018).
23. Bergh AM, Arsalo I, Malan AF, Patrick M, Pattinson RC, Phillips N. Measuring implementation progress in kangaroo mother care $A$

4. World Health Organization. Everybody's Business: Strengthening Health Systems to Improve Health Outcomes. WHO's Framework for Action. Geneva: World Health Organization, 2007. apps.who.int/iris/ bitstream/10665/43918/1/9789241596077_eng.pdf (accessed 23 March 2018).

25. Hofmann T. Spreewenspektakel Hooggraven Utrecht. 2011. https://www.youtube.com/watch?v= cQz5yNfKkSM (accessed 22 December 2015).

26. Donabedian A. Evaluating quality of medical care. Millbank Q 1966;44:166-206.

27. Leatherman S, Ferris TG, Berwick D, Omaswa F, Crisp N. The role of quality improvement in strengthening health systems in developing countries. Int J Qual Health Care 2010;22(4):237-243. https:// doi.org/10.1093/intqhe/mzq028

8. Kruger LM, Schoombie C. The other side of caring: abuse in a South African maternity ward. J Reprod Infant Psych 2010;28(1):84-101. https://doi.org/10.1080/02646830903294979

29. Lawrence HC 3rd, Copel JA, O'Keeffe DF, et al. Quality patient care in labor and delivery: A call to action. Am J Obstet Gynecol 2012;207(3):147-148. https://doi.org/10.1016/j.ajog.2012.07.018

30. Koblinsky M, Moyer CA, Calvert C, et al. Quality maternity care for every woman, everywhere: A call to action. Lancet 2016;388(10057):2307-2320. https://doi.org/10.1016/S0140-6736(16)31333-2

31. Rosen HE, Lynam PF, Carr C, Reis V, Ricca J, Bazant IS. Direct observation of respectful maternity care in five countries: A cross-sectional study of health facilities in East and Southern Africa. BMC Pregnancy Childbirth 2015;15:306. https://doi.org/10.1186/s12884-015-0728-4

32. Jewkes R, Penn-Kekana L. Mistreatment of women in childbirth: Time for action on this important dimension of violence against women. PloS Med 2015;12:e1001849. https://doi.org/10.1371/journal. pmed.1001849

33. Semrau K, Hirschhorn L, Marx Delaney M, et al. Outcomes of a coaching-based WHO Safe Childbirth Checklist program in India. N Engl J Med 2017;377(24):2313-2324. https://doi.org/10.1056/ NEJMoa1701075

34. Munabi-Babigumira S, Glenton C, Lewin S, Fretheim A, Nabudere H. Factors that influence the provision Munabi-Babigumira S, Glenton C, Lewin S, Fretheim A, Nabudere H. Factors that influence the provision
of intrapartum and postnatal care by skilled birth attendants in low- and middle-income countries: A qualitative evidence synthesis. Cochrane Database Syst Rev 2017; Issue 11. Art. No.: CD011558. https:// A qualitative evidence synthesis. Cochrane D
doi.org/10.1002/14651858.CD011558.pub2

doi.org/10.1002/14651858.CD011558.pub2
35. Cornthwaite K, Edwards S, Siassakos D. Reducing risk in maternity by optimising teamwork and Cornthwaite K, Edwards S, Siassakos D. Reducing risk in maternity by optimising teamwork and
leadership: An evidence-based approach to save mothers and babies. Best Pract Res Clin Obstet Gynaecol leadership: An evidence-based approach to save mothers and babies.

6. Chauke HL, Pattinson RC. Wardrounds - bedside or conference room? S Afr Med J 2006;96(5):398-400. 37. Edozien LC. Structured multidisciplinary intershift handover (SMITH): A tool for promoting safer intrapartum care. J Obstet Gynaecol 2011;31(8):683-686. https://doi.org/10.3109/01443615.2011.595518 8. Leonard M, Graham S, Bonacum D. The human factor: The critical importance of effective teamwork and communication in providing safe care. Qual Saf Health Care 2004;13(Suppl 1):i85-i90. https://doi. org/10.1136/qshc.2004.010033

9. Paxton A, Maine D, Freedman L, Fry D, Lobis S. The evidence for emergency obstetric care. BJOC 2005;88(2):181-193. https://doi.org/10.1016/j.ijgo.2004.11.026

40. Pattinson RC, Rhoda N. Saving Babies 2012 - 2013: Ninth Report on Perinatal Care in South Africa. Pretoria: Tshepisa Press, 2014

41. Kruk ME, Leslie HH, Verguet S, Mbaruku G, Adanu RM, Langer A. Quality of basic maternal care functions in health facilities of five African countries: An analysis of national health system surveys. Lancet Global Health 2016;4(11):e845-e855. https://doi.org/10.1016/S2214-109X(16)30180-2

42. Renfrew MJ, McFadden A, Bastos MH, et al. Midwifery and quality care: Findings from a new evidenceinformed framework for maternal and newborn care. Lancet 2014;384(9948):1129-1145. https://doi. org/10.1016/S0140-6736(14)60789-3

43. Mduma E, Ersdal H, Svensen E, Kidanto H, Auestad B, Perlman J. Frequent brief on-site simulation training and reduction in 24 -h neonatal mortality - an educational intervention study. Resuscitation 2015;93:1-7. https://doi.org/10.1016/.j.resuscitation.2015.04.019

44. Oladapo OT, Souza JP, Bohren MA, et al. WHO Better Outcomes in Labour Difficulty (BOLD) project: Innovating to improve quality of care around the time of childbirth. Reprod Health 2015;12:48. https:// doi.org/10.1186/s12978-015-0027-6

Accepted 3 August 2018. 